\title{
THE IMPACT OF KNOWLEDGE MANAGEMENT PRACTICES ON SUPPLY CHAIN QUALITY MANAGEMENT AND COMPETITIVE ADVANTAGES
}

\author{
Reihaneh Azizi ${ }^{1}$, Meysam Maleki ${ }^{2}$, Mohsen Moradi-Moghadam ${ }^{1}$, Virgilio Cruz-Machado ${ }^{2}$ \\ ${ }^{1}$ Faculty of Management, University of Tehran, Iran \\ ${ }^{2}$ UNIDEMI, Department of Mechanical and Industrial Engineering, Faculty of Science and Technology, Universidade \\ Nova de Lisboa, Portugal
}

Corresponding author:

Reihaneh Azizi

Faculty of Management

University of Tehran

6311-14155 Tehran, Iran

phone: (+98 21) 8216-1347

e-mail: azizi_reyhane@yahoo.com

Received: 17 November 2015

Accepted: 28 February 2016

\begin{abstract}
Achieving competitive advantage enables an organization to create a defensible position against its competitors. It also allows organizations to differentiate themselves from competitors. This study aims to investigate impact of knowledge management practices on supply chain quality management and competitive advantage in Alyaf Company, Iran. This research is functional in purpose and data gathering and data analysis is descriptive-correlation. The statistical population is consists of 25 company executives and experts in the supply chain of Alyaf Company; opinions of 68 of its members were used as a selective sample identified by simple random sampling method. Primary data was collected through questionnaire and structural equation modeling was used to assess relationships between variables. The results of structural equation modeling show a positive and significant causal relationship between knowledge management practices and supply chain quality management. Direct relationship between knowledge management and competitive advantage was not confirmed but the relationship between these two variables was confirmed indirectly.
\end{abstract}

KEYWORDS

knowledge management practices, supply chain quality management, structural equation modeling.

\section{Introduction}

The fact that companies who ignore their resources indeed use a white paper that has nothing on it, as their strategy, is stressed in the literature. Competitive environment of today's organizations, more than ever, is complex, varied and extensive that the preservation and promotion of sustainable competitive advantage, is a major concern for managers. In the recent decades, the role of knowledge in competitiveness of organizations has been highlighted, in fact, the value often achieved not only by the equipment and facilities, but also by the knowledge accumulated in that organization. Nowadays organizations consider the knowledge as the most valu- able and strategic resource [1] and believe in order to remain competitive, they must manage their own ability and intellectual resources. The organization will be successful in today's competitive world, which accounted for a larger share of their organizational knowledge [2]. In this way, the knowledge base is the only basis for achieving competitive advantage and its sustainability is subject to good management.

As global markets grow, supply chain managers are faced with continuously changing market, new global markets and competitive environment. Today organizations operate beyond national borders, so they cannot just rely on their internal quality activities. While the world has recognized the importance of quality management, researchers need a more fo- 
cused approach in assessing the quality of the supply chain management issues, internal and external integrate the principles of quality management offers potential solutions to broaden the perspective of supply chain management from focus on costs and competitive relationships to focus on collaboration between members of the supply chain and the strategic importance of supply chain management to achieve competitive advantage $[3,4]$.

Modernization of supply chain activities depend on the support of the knowledge and use some mechanisms that create this knowledge, share among supply chain members, use this knowledge and Finally a way to store this knowledge to be used in the future. If the mechanisms exist in the organizations and in particular in the supply chain, can be improved and excellence in supply chain activities. Through the processes of knowledge management and quality management, the need for rework and cycle time reduce [5] and thereby leads to better planning and faster response to market demands and then can bring competitive advantage based on customer, technology and integration of activities to the company.

This paper is structured as follows: in the second section, literature review of the knowledge management, supply chain quality management and competitive advantage as well as empirical research literature is reviewed. The third section include the conceptual model contains parameters defining the knowledge management, supply chain quality management and competitive advantage is based on the research literature and defines the relationship between them. In the data analysis section the relationships based on structural equation modeling was used to verify main assumptions underlying the present study and research findings are presented in the next section. After discussion section, conclusion will be described in the final section.

\section{Literature review}

Knowledge has been perceived as meaningful information, and defined as combination of flexible and conversion of experience, values, combined information, and expert insight that provides a framework for assessing and integrating new experiences and data have defined [6]. Between two dimensions of knowledge (i.e., tacit and explicit), tacit knowledge leads to a sustainable competitive advantage [7]. Also based on another classification of knowledge (i.e., organizational knowledge versus individual knowledge), organizational knowledge is created through a continuous dialogue between tacit and explicit knowledge [8]. Nevertheless, existent and new knowledge need to be organized in a manner that makes it usable.

Newman offers a general model of knowledge. In this model, knowledge is organized in four areas [9]. Basic processes of knowledge-based organization include:

- creation and acquisition of knowledge,

- knowledge sharing,

- organizing and storing knowledge,

- application of knowledge.

To succeed in today's world, managers need to integrate their goals with dynamic and global economy and think about final consumers and this is the unique thought that is followed by quality management and total quality management at the ideal level [10]. Stiller et al. [11] study the quality management and supply chain in different parts of the supply chain such as supply chain design, demand planning, scheduling procedures and procurement, inventory management and control and supply chain planning and control.

Quality management plays an important role in many processes of the supply chain design such as supplier identification, selection of suitable locations for production, supply chain demand planning, taking the right decisions about operations that have been mentioned in the literature $[10,12,13]$. Also the role of quality management is obvious in procedures planning and supply chain inventory control. In studies, analyzes of $\mathrm{ABC} / \mathrm{XYZ}$ are noted that have pursued the sourcing policies and have considered timely delivery, also the quality of inventory control is emphasized [14, 15]. Also supply chain and customer relationship management has been studied from the perspective of quality management [16]. In this discussion, customer is not only the final customer, but with a view of the process, each member of the supply chain is a customer for another member and it should have been established win-win relationships between partners and move towards the goals of the supply chain $[10,17,18]$. Total quality management (TQM) and supply chain management (SCM) have played an increasing role in recent years in strengthening the competitiveness of enterprises.

In today's competitive market producing highquality products is not enough and new challenges are more focused on the delivery of the goods at the suitable time and place $[19,20]$. Competition among businesses in the international arena is not only between organizations but also through their supply chain $[21,22]$. In this regard, quality as a strategic variable has attracted the attention of many experts so that most experts believe that by moving 
the competitiveness from the companies to their supply chain, quality and quality management must be transferred from the corporate level to the supply chain level because as a commodity is moving from one member to another member of the supply chain, the quality can also be affected by every member of the chain and so must view the traditional quality management plans from the perspective of supply chain Because supply chain management with making effective communication between supply chain partners, provides an opportunity and a platform for them that will be able to improve the quality of the products and services and increase the quality and supply chain performance and also the quality of the final product with the institutionalization of quality throughout the supply chain and to attract more customers, gain a competitive advantage [20].

According to a survey of models and various articles, in total 22 indicators were identified to measure the quality of the supply chain that according to the literature review these indicators can be classified in 7 areas. The identified indicators regarding to the relevant areas and research resources are shown in Table 1 [23].

Table 1

List of sub-constructs for supply chain quality management.

\begin{tabular}{|c|c|c|}
\hline Variables & Dimension & Concepts \\
\hline \multirow{22}{*}{ 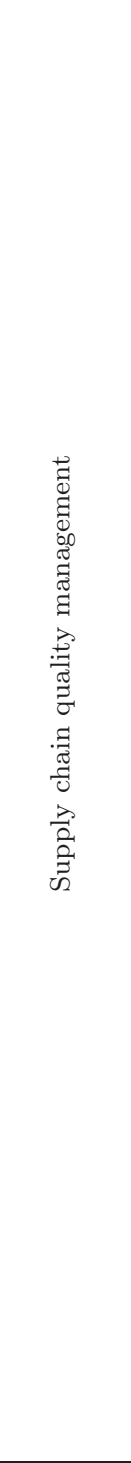 } & \multirow{3}{*}{ Customer focus } & $\begin{array}{l}\text { Mechanisms, infrastructure and tools is created that are needed to manage the rela- } \\
\text { tionship with customers in the system }\end{array}$ \\
\hline & & $\begin{array}{l}\text { Monitoring and identifying the needs and expectations of actual and potential cus- } \\
\text { tomers are done effectively and consistently }\end{array}$ \\
\hline & & The knowledge of the directors and staff of the results of customer satisfaction studies \\
\hline & \multirow{4}{*}{$\begin{array}{l}\text { Supplier quality } \\
\text { management }\end{array}$} & $\begin{array}{l}\text { Mechanisms, infrastructure and tools is created that are needed to manage the rela- } \\
\text { tionship with suppliers in the system }\end{array}$ \\
\hline & & Select the suppliers based on quality compared to other criteria such as price \\
\hline & & Organization have a comprehensive system of evaluation and ranking of suppliers \\
\hline & & Suppliers are involved in the processes of design and development of product quality \\
\hline & \multirow{4}{*}{$\begin{array}{l}\text { Supply chain } \\
\text { management } \\
\text { leadership }\end{array}$} & $\begin{array}{l}\text { The leadership and quality management of supply chain can be concentrated in one } \\
\text { part of the company }\end{array}$ \\
\hline & & $\begin{array}{l}\text { Commitment, support and involvement of senior management in relation to the qual- } \\
\text { ity of the supply chain }\end{array}$ \\
\hline & & $\begin{array}{l}\text { The senior management effort of the supply chain to create a culture of quality and } \\
\text { quality policy in the supply chain }\end{array}$ \\
\hline & & $\begin{array}{l}\text { The knowledge and ability of senior management to quality and quality management } \\
\text { in the supply chain }\end{array}$ \\
\hline & \multirow{2}{*}{$\begin{array}{l}\text { Supply chain } \\
\text { quality } \\
\text { strategies }\end{array}$} & $\begin{array}{l}\text { Alignment between quality management strategies and supply chain management } \\
\text { strategies }\end{array}$ \\
\hline & & $\begin{array}{l}\text { Preparing and reviewing the supply chain quality strategies in collaboration with } \\
\text { other members of the chain }\end{array}$ \\
\hline & \multirow{3}{*}{ Process approach } & Integration and compatibility between the various processes in the supply chain \\
\hline & & $\begin{array}{l}\text { Cooperation and partnership with other companies involved in the design and con- } \\
\text { tinuous improvement of quality of processes in the supply chain sourcing (supplier } \\
\text { selection) }\end{array}$ \\
\hline & & $\begin{array}{l}\text { Cooperation and partnership with other companies involved in the supply chain in } \\
\text { the design and continuous improvement of product design processes }\end{array}$ \\
\hline & \multirow{3}{*}{$\begin{array}{l}\text { Supply chain } \\
\text { information } \\
\text { systems }\end{array}$} & $\begin{array}{l}\text { Use of information and communications systems and technologies identified in the } \\
\text { supply chain }\end{array}$ \\
\hline & & $\begin{array}{l}\text { The ability of information systems in the documentation of product processes in the } \\
\text { supply chain }\end{array}$ \\
\hline & & $\begin{array}{l}\text { The ability of information systems on a regular and timely reporting of information } \\
\text { relating to product quality, such as quality spending }\end{array}$ \\
\hline & \multirow{3}{*}{$\begin{array}{l}\text { Human recourse } \\
\text { development }\end{array}$} & Empower and educate employees on issues related to quality \\
\hline & & $\begin{array}{l}\text { Formed teams to resolve quality issues with representatives of companies in the supply } \\
\text { chain }\end{array}$ \\
\hline & & $\begin{array}{l}\text { The similarity and integrity in the common quality culture among company employees } \\
\text { with common quality culture among employees of other companies in the chain }\end{array}$ \\
\hline
\end{tabular}


Most attempts to explain the theoretical framework of competitive advantage took place in the mid-twentieth century leading to various perspectives; Michael Porter is the best-known experts in this view and he can be called the father of this view. The first view searches the competitive advantage resources beyond borders and industry is a unit of analysis and structural and content features make the organization to achieve competitive advantage and higher profits than the average. In contrast, there is resource-based view that this attitude is basically known an organization as the unit of analysis and states the characteristics of organizational resources as a source of competitiveness and stabilization. Proponents of this view in an effort to overcome its limitations, have offered new perspectives including merit-based competition perspective and the perspective of competition on the dynamic capabilities that Teece, Hamel and Barney can be named as some most famous theorists in this perspective.

Li Suhong et al. [4] collected some data from 196 organizations and the relationships proposed in the framework were tested using structural equation modeling. The results indicate that higher levels of SCM practice can lead to enhanced competitive advantage and improved organizational performance. Also, competitive advantage can have a direct, positive impact on organizational performance. In the present study, the competitive advantage indicators used is extracted from this article.

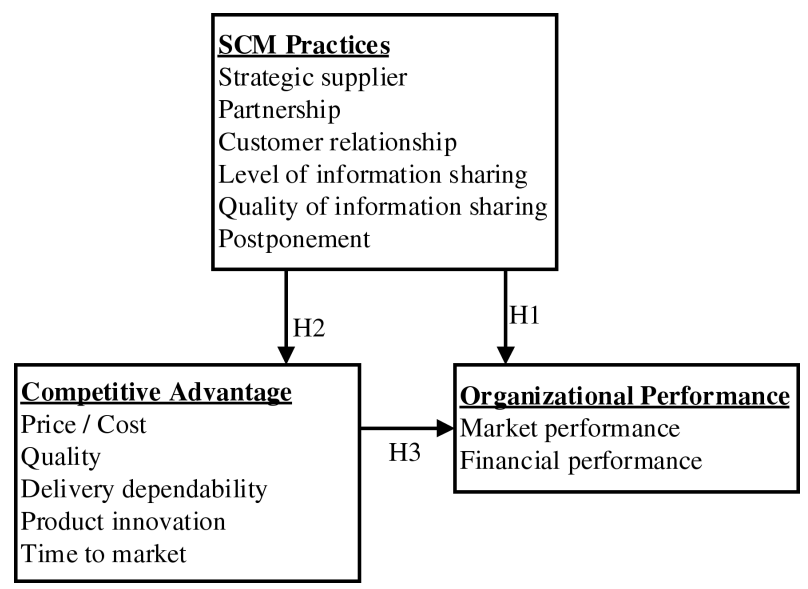

Fig. 1. Indicators of competitive advantage.

The impact of knowledge management practices on supply chain quality management, has been the subject of many experimental studies. These include a variety of definitions of knowledge management, supply chain quality management, measurement and methods. For example Patil and Kant [24] showed that the adoption of knowledge management in the supply chain requires high investment and changes in the culture of the entire supply chain. The study predicts a framework to adopt knowledge management in supply chain based on DEMATEL technique and FMCDM. Also the relationship between members of the supply chain, knowledge transfer and value added in supply chain, teamwork based on trust for the exchange of knowledge in supply chain, employee participation and support from senior management are five of the most important criteria for successful adoption of knowledge management in the supply chain. In another study, solutions for adoption of knowledge management in the supply chain to overcome strategic, organizational, technological, cultural and personal barriers and focus on better solutions and develop strategies for their implementation are identified and prioritized and presents a framework based on the AHP and TOPSIS technique to identify and rank the solutions to overcome barriers to the adoption of knowledge management in the supply chain [25].

Collins et al. [26] propose knowledge management as a key enabler of supply chain management and a critical element in corporate environments and high volume of information.

Durst and Runar Edvardsson [27], have examined knowledge management among small and medium organizations' supply chain management. They consider that it is necessary the relationship of internal organization for the exchange of knowledge between companies and their supply chain and know it is possible specific knowledge creation through increased confidence and motivation. They believe that knowledge is an important factor to achieve a competitive advantage among supply chain competitors.

Andreeva and Kianto [28] have examined the impact of sharing knowledge management practices on better integrating between supply chain partners and state that this cooperation can increase the quality of organizational knowledge. They believe that in today's competitive environment, the supply chain must respond quickly to changes in customer demand and is not possible except with the transmission of data, sharing knowledge and building relationships based on trust and cooperation.

$\mathrm{Wu}[29]$, states that the creation of value through supply chain integration is a valuable potential way to provide competitive advantage and organizational performance improvement, because the competition is not only between organizations but also between their supply chains. Supply chain integration focuses not only on resources and tangible assets but also intangible resources such as knowledge. In fact, the knowledge is the only proper source for competitive advantage, growth and continuous progress for sup- 
ply chain partners. He argues that knowledge creation in the supply chain affect by customer relationship management (CRM), research and development with the approach of customer-orientation and clarification of roles and responsibilities as well as suppliers relationship management (SRM).

\section{Research methodology}

The theoretical framework is a conceptual model that is based on the theoretical relationships between several factors that have been identified as important issues of research. The theoretical framework flows logically with the study of history related to the issue. Hence, Fig. 2 shows conceptual model and research hypotheses. Conceptual model includes parameters defining knowledge management, supply chain quality management and competitive advantage based on the research literature and states the relationship between them. By creating a conceptual framework for research to exami-

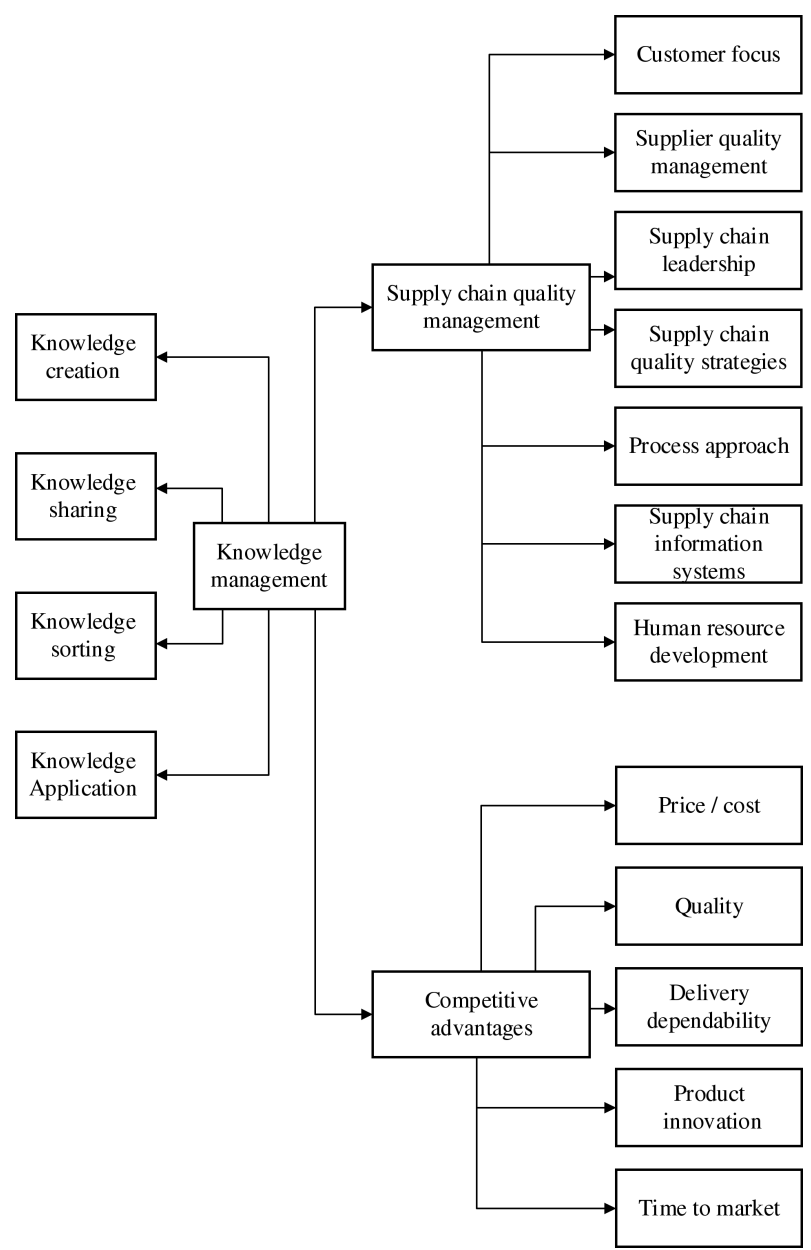

Fig. 2. Conceptual model. ne the impact of knowledge management practices on supply chain quality management and competitive advantage in the synthetic fiber industry, all research goals and questions addressed in this framework will be examined. Knowledge management has 4 sub-constructs, supply chain quality management has 7 sub-constructs and competitive advantage has 5 sub-constructs that the relationship between them are shown in Fig. 2 according to research conducted by Newman [30], Kaynak and Hartley [31], Safari and Mohebbimannesh [23] and Li Suhong et al. [4].

\section{Data analysis}

The relationships based on structural equation modeling were used in order to verify the assumptions underlying the study. The hypotheses of this study are as follows:

H1: knowledge management has a significant impact on the supply chain quality management.

H2: knowledge management has a significant impact on the competitive advantage.

H3: supply chain quality management has a significant impact on the competitive advantage.

H4: knowledge management through the supply chain quality management has a significant impact on the competitive advantage.

According to the research hypothesis is stated above, knowledge management were identified as independent variable, supply chain quality management were identified as mediator and competitive advantage were identified as dependent variable. The relationship between these variables shown in Fig. 3 according to the research hypotheses in the conceptual model.

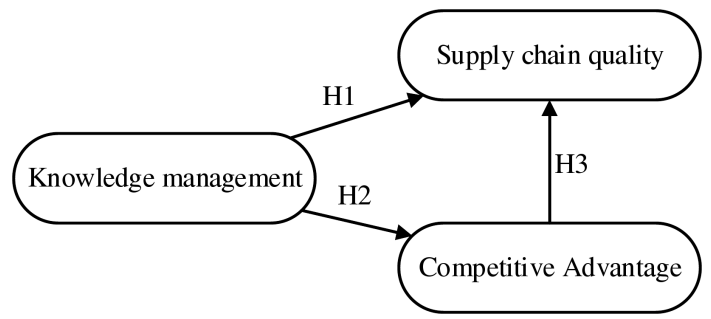

Fig. 3. Research conceptual model.

\section{Findings}

By using the results of the internal model of the Smart PLS, as shown in the figure, can examine the research hypotheses. Statistical measures of $T$, the coefficient of determination and path coefficient is used to evaluate the model. Figure 4 shows the statistic $\mathrm{T}$ in the internal model. 


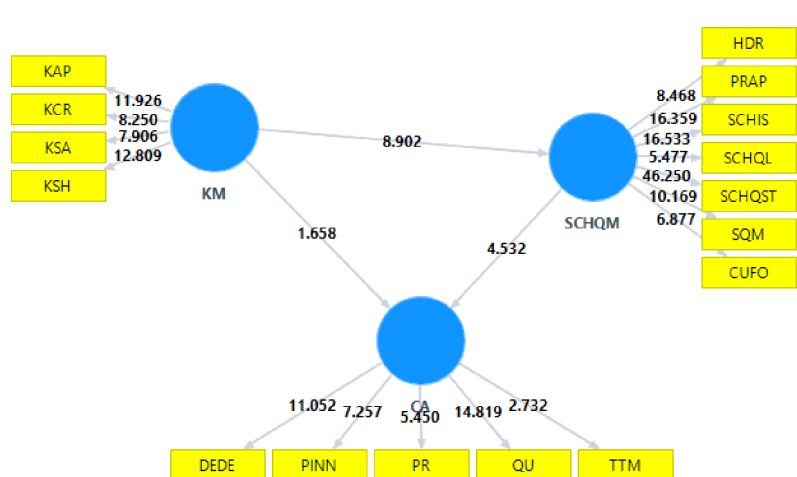

Fig. 4. T-Statistics in the internal model of Smart PLS.

Figure 5 shows the path coefficient of the structural model. Numbers written on the lines are standardized beta coefficients in ordinary least squares regression that in fact, they are the path coefficients in the PLS structural model. Path coefficients should be examined of the sign, magnitude and significance. Positive path coefficients indicate positive effects (direct relationship between the two constructs) and a negative sign indicates a negative effect between two constructs (inverse relationship). In terms of magni-

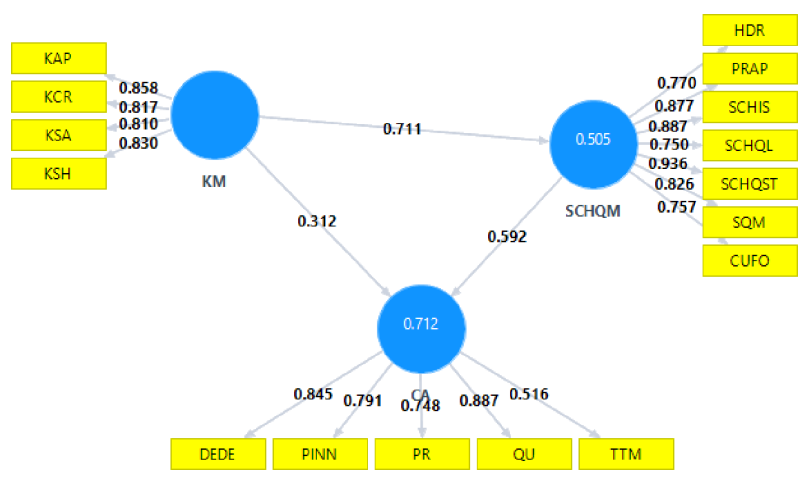

Fig. 5. Path coefficients in the internal model of Smart PLS. tude, impact factor of a construct to other constructs decreases by the increasing of the number of indirect routes [32].

Research tested model showed, just one of the research hypothesis was not confirmed according to the statistic $\mathrm{T}$. $\mathrm{T}$ values for each path and the path coefficients are presented in Table 2.

Calculating direct, indirect and total effect of model variables is required to evaluate direct and indirect effects of the independent variables on the dependent (Table 2). The total effect includes the sum of direct and indirect effects between constructs. Direct effect is the same as path coefficient and indirect effect is obtained by subtracting between the total effect and direct effect.

Total effect $=$ direct effect + indirect effect

The greatest effect is seen in Table 3, is the impact of knowledge management on competitive advantage (0.73). It has a large positive effect and is equivalent to the sum of the direct and indirect effects. The least effect is for supply chain quality management on competitive advantage, although all of the effects due to the amount of P-Value and Tstatistics are significant.

The basic criterion for evaluation of endogenous latent variables is the coefficient of determination $\mathrm{R}^{2}$. $\mathrm{R}^{2}$ values equal to $0.67,0.33$ and 0.19 , respectively, are described substantial, moderate, weak. If the structure of an internal given route model explain an endogenous latent variable with a small number (one or two) of the exogenous latent variables, $\mathrm{R}^{2}$ moderate is acceptable. But if the endogenous latent variables are dependent on exogenous latent variables, the value of $\mathrm{R}^{2}$ should at least be noticeable. This means more than 0.67 . Otherwise, doubts are raised about the underlying theoretical model and show that model is unable to describe the endogenous latent variable [32].

Table 2

The results of the structural model test.

\begin{tabular}{|c|c|c|c|}
\hline Hypotheses & Path coefficient & T-Statistical & Result \\
\hline Knowledge management $\rightarrow$ supply chain quality management & 0.71 & 8.90 & Accept \\
\hline Knowledge management $\rightarrow$ competitive advantage & 0.31 & 1.66 & Reject \\
\hline Supply chain quality management $\rightarrow$ competitive advantage & 0.59 & 4.53 & Accept \\
\hline $\begin{array}{l}\text { Knowledge management } \rightarrow \text { competitive advantage through supply chain quality } \\
\text { management }\end{array}$ & 0.42 & 3.85 & Accept \\
\hline
\end{tabular}

Table 3

Total, direct and indirect effects.

\begin{tabular}{|c|c|c|c|c|c|}
\hline P-Value & Direct effect & Indirect effect & Total effect & T-Statistical & P-Value \\
\hline Knowledge management $\rightarrow$ competitive advantage & 0.31 & 0.42 & 0.73 & 5.88 & 0.00 \\
\hline $\begin{array}{l}\text { Knowledge management } \rightarrow \text { supply chain quality man- } \\
\text { agement }\end{array}$ & 0.71 & - & 0.71 & 8.90 & 0.00 \\
\hline $\begin{array}{l}\text { Supply chain quality management } \rightarrow \text { competitive ad- } \\
\text { vantage }\end{array}$ & 0.59 & - & 0.59 & 4.53 & 0.00 \\
\hline
\end{tabular}


Figure 6 shows the coefficient of determination in the structural model.

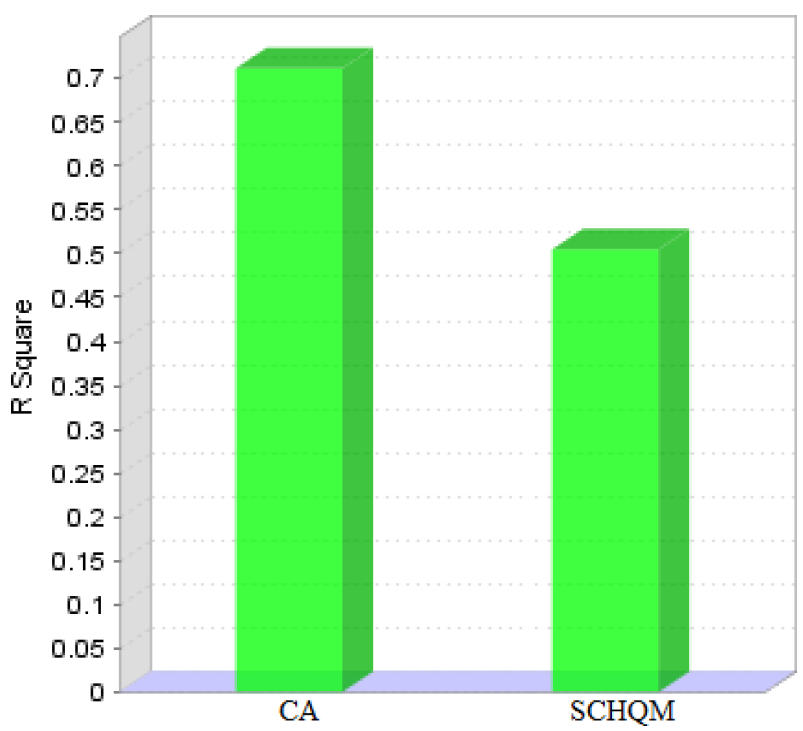

Fig. 6. $\mathrm{R}^{2}$ values in the internal model of Smart PLS

As shown in Fig. 6, the numbers indicate $\mathrm{R}^{2}$ values for assessing latent variables and $\mathrm{R}^{2}$ value is at an acceptable level for the latent variables. As is known, knowledge management can predict about $50 \%$ of supply chain quality management. Similarly, knowledge management and supply chain quality management can anticipate about $71 \%$ of the changes in competitive advantage.

\section{Discussions}

The results show that the dimensions of supply chain quality management have an intermediate position. This indicates that with respect to the activities undertaken in the past, there is still need more to improve the quality of the supply chain in Alyaf Company. Also the knowledge management in the studied population is in a bad situation. This reflects the knowledge management practices in the company's supply chain are not in a good condition and there is a need for greater coherence and better measures. The use of knowledge management systems can be contributed to the promotion of quality of supply chain. Hence the fact that some components of knowledge management as well as indicators of supply chain quality management in the studied population are not in a good condition, these indicators can be improved through the establishment of knowledge management systems to create, share, use and storage of knowledge in the company's supply chain and make it easy to obtain competitive advantage for the company.
In the lower level of analysis, creation, sharing and storage of knowledge have an intermediate situation and still need more and better work in the field of knowledge creation in supply chain, sharing and strategies for maintenance and re-operation in the company's supply chain. Also, the application of knowledge is in a bad situation, which indicates that the knowledge in supply chain is not used well in the company.

Also in the supply chain quality management, quality management of suppliers, leadership of supply chain quality and supply chain information systems are in an intermediate state. This also indicates that there is still a need for some activities to improve channels of communication with suppliers and how they are selected. Also supporting by senior management of supply chain quality management should be taken to be continuous. Finally, it is necessary to utilizes information technology for mechanize and modernize the company's supply chain.

\section{Conclusions}

After the current state variables and related indicators were identified, the research hypotheses can be examined.

Hypothesis 1 indicates a positive and significant relationship between "knowledge management" and "supply chain quality management". The relationship between these two variables is 0.711 . The results indicate that the "knowledge management' can predict about 51 percent of variation in "supply chain quality management". So, the hypothesis is accepted and it can be stated that the promotion of "knowledge management" in the subject population of $5 \%$ error level can improve "supply chain quality management".

Hypothesis 2 indicates the absence of a positive and significant relationship between "knowledge management" and "competitive advantage". The relationship between these two variables is 0.31.The results indicate that changes in the competitive advantage cannot be explained directly by the knowledge management in the company. So, the hypothesis is rejected.

Hypothesis 3 indicates a positive and significant relation between "supply chain quality management" and "competitive advantage". The relationship between these two variables is 0.592 . In fact, the results indicate that "supply chain quality management" can predict about $35 \%$ of the variation in "competitive advantage". So, the hypothesis is accepted. Therefore it can be stated that the promotion of "supply chain quality management" in the subject 
population of $5 \%$ error level can improve "competitive advantage".

Hypothesis 4 indicates that knowledge management through the supply chain quality management has a significant impact on the competitive advantage. So, hypothesis 4 is approved. The indirect relationship between these two variables is 0.42 . In other words, we can say that $18 \%$ of changes in competitive advantage can anticipate by knowledge management through supply chain quality management.

The main results show that knowledge management will not affect the competitive advantage of the company by itself. In other words, taking advantage of the tools and knowledge management systems cannot bring amazing results by itself for these companies and in the first place it is necessary to apply the initial activities of implementation and knowledge application in the organization. In general, we can suggest that to facilitate the achievement of competitive advantage, primarily management should identify and pursue the strengths and weaknesses of knowledge management programs. Then they should accordance supply chain quality management system with knowledge management system by the creation of mechanisms and processes of knowledge management and in this way they can lead to achieving the company's competitive position based on the supply chain activities.

Authors would like to appreciate cooperation and support of CEO and staff of Alyaf Company. Also, UNIDEMI authors would like to thank the Fundação para a Ciência e Tecnologia, Project: UID/EMS/00667/2013 for funding this research work.

\section{References}

[1] Zack M.H., The strategic advantage of knowledge and learning, International Journal of Learning and Intellectual Capital, 2, 1, 1-20, 2005.

[2] Moshabaki A., Rabieh M., Organizational forgetting (strategic): panacea of competitiveness in the organization, Faslnameye modarese olome ensani, 2008.

[3] Maleki M., Cruz-Machado V., An empirical review on supply chain integration, Management and Production Engineering Review, 4, 1, 85-96, 2013.

[4] Li Suhong, Ragu-Nathanb Bhanu, Ragu-Nathanb T.S., Subba Rao S., The impact of supply chain management practices on competitive advantage and organizational performance, Omega, 32, 2, 107-124, 2006.

[5] Maleki M., Cruz-Machado V., Supply chain performance monitoring using bayesian network, Interna- tional Journal of Business Performance and Supply Chain Modelling, 5 (2), 177-197, 2013.

[6] Davenport T.H., Prusak L., Working Knowledge: How Organizations Manage What the Know, Boston, Massachusetts, Harvard Business School Press, 1998.

[7] Weber B., Weber C., Corporate venture capital as a means of radical innovation: relational fit, social capital, and knowledge transfer, Journal of Engineering \& Technology Management, 24, 1/2, 11-35, 2007.

[8] Nonaka I., von Krogh G., Voelpel S., Organizational Knowledge Creation Theory: Evolutionary paths and future advances, Organization Studies, 27, 8, 1179-1208, 2006.

[9] Amini A., The impact of social capital on knowledge management cycle, Tehran: Tehran University, Faculty of Management, 2007.

[10] Fish L.A., Supply chain management - pathways for research and practice, Edited by Dilek Önkal and Emel Aktas, InTech, chapter 3, Supply Chain Quality Management, ISBN 978-953-307-294-4, 2011.

[11] Stiller S., Falk B., Philipsen R., Brauner P., Schmitt R., Ziefle M., A game-based approach to understand human factors in supply chains and quality management, Procedia of 2nd International Conference on Ramp-Up Management 20, 67-73, 2014.

[12] Brauner P., Runge S., Groten M., Schuh G., Ziefle M., Human factors in supply chain management decision making in complex logistic scenarios, in Proceedings of the 15th HCI International 2013, Part III, LNCS 8018, 2013. 423-432, 2013.

[13] Monczka R.M., Handfield R.B., Giunipero L.C., Patterson J.L., Purchasing and Supply Chain Management, Fourth Edition, South-Western Cengage Learning, Mason, OH, 2009.

[14] Murphy W.H., Bull's-eye, Quality Progress, 43 (6), 22-29, 2010.

[15] Lee K., Wei C., Lee H., Reducing exposed copper on annual rings in a $P C B$ factory through implementation of a Six Sigma project, Total Quality Management \& Business Excellence, 20 (8), 863-876, 2009.

[16] Maleki M., Shevtshenko E., Cruz-Machado V., Development of Supply Chain Integration model through application of Analytic Network Process and Bayesian Network, International Journal of Integrated Supply Management, 8 (1/2/3), 67-89, 2013.

[17] Foster S.T. Jr., Ogden J., On differences in how operations and supply chain managers approach quality management, International Journal of Production Research, 46 (24), 6945-6961, 2008. 
[18] Flynn B.B., Flynn E.J., Synergies between supply chain management and quality management: emerging implications, International Journal of Production Research, 43 (16), 3421-3436, 2005.

[19] Shin H., Collier D.A., Wilson D.D., Supply management orientation and supplier/buyer performance, Journal of Operations Management, 18, 317-333, 2002.

[20] Robinson C.J., Malhotra M.K., Defining the concept of supply chain quality management and its relevance to academic and industrial practice, International Journal of Production Economics, 96, 315-37, 2005.

[21] Lee Y.C., Lee S.K., Capabilities, processes, and performance of knowledge management: a structural approach, Human Factors and Ergonomics in Manufacturing, 17 (1), 21-41, 2007.

[22] Kuei C.H., Madu C.N., Lin C., Implementing supply chain quality management, Total Quality Management, 19 (11), 1127-1141, 2008.

[23] Safari H., Mohebimanesh O., A conceptual model of supply chain quality management and evaluation of the situation in Iran khodro, Tehran: Tehran University, Faculty of Management, 2011.

[24] Patil S.K., Kant R., A hybrid approach based on fuzzy DEMATEL and FMCDM to predict success of knowledge management adoption in supply chain, Applied Soft Computing, 18, 126-135, 2014.

[25] Safari H., Cruz-Machado V., Zadeh Sarraf A., Maleki M., Multidimensional personnel selection through combination of TOPSIS and Hungary assignment algorithm, Management and Production Engineering Review, 5, 1, 42-50, 2014.

[26] Collins J.D., Worthington W.J., Reyes P.M., Romero M., Knowledge management, supply chain technologies, and firm performance, Management Research Review, 33 (10), 947-960, 2010.

[27] Durst S., Runar Edvardsson I., Knowledge management in SMEs: a literature review, Journal of Knowledge Management, 16 (6), 879-903, 2012.

[28] Andreeva T., Kianto A., Does knowledge management really matter? Linking knowledge management practices, competitiveness and economic performance, Journal of Knowledge Management, 16 (4), 617-636, 2012.

[29] Wu C., Knowledge creation in a supply chain, Supply Chain Management: An International Journal, 13 (3), 241-250, 2008.

[30] Newman A., Knowledge management. American Society for Training and Development, ASTD, New York, 1999.

[31] Kaynak H., Hartley H.J.L., A replication and extension of quality management into the supply chain, Journal of Operations Management, 26 (4), 468-89, 2008.

[32] Azar A., Momeni M., Statistics and Its Application in Management, Tehran: Sazmane motalee va tadvine kotobe olome ensani daneshgahha, 2012. 